\title{
Interfaces epistemológicas sobre administração pública, institucionalismo e capital social
}

\author{
Epistemological interfaces on public administration, institutionalism and social capital
}

\author{
Edson Arlindo Silva1 \\ José Roberto Pereira2 \\ Valderí de Castro Alcântara3
}

\section{Resumo}

A sociedade contemporânea é marcada pela presença de instituições que organizam, normatizam e regulamentam as relações sociais de trabalho. Ao mesmo tempo que as instituições podem ser pensadas individualmente, também possuem a capacidade de se organizar em redes objetivando o fortalecimento de laços intra e interinstitucionais. Diante deste contexto, procura-se, aqui, realizar uma incursão teórica entre administração pública, institucionalismo e capital social, mostrando as possíveis interfaces conceituais, com o intuito de elucidar as contribuições do institucionalismo e do capital social para melhor compreender a administração pública contemporânea. Por um lado, a teoria do capital social favorece o entendido sobre o conjunto de investimentos que são canalizados em ações socioeconômicas e culturais para atender demandas sociais específicas advindas de grupos organizados da sociedade civil. Assim, segundo as premissas do capital social os indivíduos se relacionam uns com os outros para ter acesso aos recursos públicos coletivos almejando a consecução de diversos interesses comuns. Já no institucionalismo parte-se da premissa de que qualquer instituição, formalmente constituída e legitimamente reconhecida pelos atributos legais da sociedade, perde a razão de ser quando sua lógica de constituição não consegue ser mais eficiente do que qualquer ação individual isolada. Por fim, as discussões em torno das temáticas do capital social, institucionalismo e modelos de administração pública nos convidam a refletir sobre as mudanças ocorridas nas sociedades modernas, principalmente no que se refere às formas de governo e às tendências das relações entre Estado e sociedade que vêm ocorrendo no mundo globalizado.

Palavras-chave: Administração pública. Capital social. Institucionalismo.

\section{Abstract}

Contemporary society is marked by the presence of institutions that organize, regulate and govern the social relations of work. While institutions can be designed individually, they also have the ability to organize into networks that aim to strengthen intra and inter- institutions. Given this context, the aim here is to perform a theoretical incursion into public administration, institutionalism and social capital, showing the possible conceptual interfaces in order to elucidate the

Artigo submetido em 13 de julho de 2010 e aceito para publicação em 19 de julho de 2011.

1 Doutor em Administração pela Universidade Federal de Lavras/UFLA; Professor adjunto da Universidade Federal de Viçosa. Endereço: Universidade Federal de Viçosa, Departamento de Administração (UFV/DAD), Campus Universitário, CEP 36570-000, Viçosa - MG, Brasil. E-mail edsonsilva@ufv.br

2 Doutor em Sociologia pela Universidade de Brasília/UNB; Professor adjunto do Departamento de Administração e Economia da Universidade Federal de Lavras. Endereço: Universidade Federal de Lavras (UFLA), Departamento de Administração e Economia, Campus Universitário, CEP 37200-000, Lavras - MG, Brasil. E-mail jpereira@ufla.br

${ }^{3}$ Graduando do Curso de Administração pela Universidade Federal de Viçosa - Campus Rio Paranaíba. Endereço: Universidade Federal de Viçosa (UFV/CRP), Campus Rio Paranaíba, Rodovia BR 354, Km 310, CEP 38810-000, Rio Paranaíba - MG, Brasil. Email valderi.alcantara@ufv.br 
contributions of institutional and social capital to better understand contemporary public administration. On the one hand, the theory of social capital promotes understanding of the set of investments that are channeled into socioeconomic and cultural activities to meet specific social needs arising from organized groups in civil society. Thus, according to the assumptions of the capital, people interact with each other for access to public resources in order to achieve the collective targeting of several common interests. Meanwhile, institutionalism sets out on the assumption that any institution that is formally constituted and legitimately recognized by the legal attributes of society loses when the reason for the logic of its constitution can no longer be any more effective than individual action alone. Finally, the discussions surrounding the themes of social capital, institutional and public administration models invite us to reflect on the changes that take place in modern societies, especially regarding forms of government and trends in relations between state and society that take place in a globalized world.

Keywords: Public administration. Social capital. Institutionalism.

\section{Capital Social no Contexto Institucional}

Os fundamentos teóricos que deram base à construção moderna do conceito de "capital social" encontram nos trabalhos de Bourdieu (1986) e Coleman (1990) a inspiração necessária para trazer à tona problemas pontuais inerentes aos modelos de administração pública experimentados pelo Brasil.

Assim, é preciso ressaltar que a evolução do conceito de "capital social", ainda em processo de consolidação como campo de estudo, relaciona-se intimamente aos estudos de Bourdieu (1986) e Coleman (1990). Estes autores influenciaram significativamente os estudos, por exemplo, de Robert Putnam, que empreendeu uma valiosa pesquisa em regiões selecionadas da Itália moderna para compreender dimensões analíticas como a descentralização política, o desempenho institucional, a confiança social e a força do processo civilizatório na transformação político-cultural de uma determinada sociedade.

A noção de capital social proposta por Putnam (2002) ganhou destaque internacional com os estudos sobre a Itália moderna em contextos regionais marcados por profundas transformações político-culturais. Ao estudar os princípios e valores da democracia italiana, Putnam (2002) constatou a existência de associações comunitárias e de práticas sociais de reciprocidade como elementos essenciais à democracia e à conscientização cívica. Assim, esses elementos não apenas garantem o caráter democrático da sociedade civil, mas também determinam o desempenho dos governos locais e de suas instituições.

Putnam (2002, p. 67) refere-se ao capital social como o conjunto de "elementos de organização social como as redes, normas e confiança social que facilitam a coordenação e a cooperação em benefício recíproco", contribuindo de maneira significativa para a superação dos dilemas da ação coletiva. Em contrapartida, Reis (2003), ao se apoiar nos críticos da teoria do capital social de Putnam, observa pontos de fragilidade em termos de definição que comprometem a consistência do conceito de "capital social".

Contudo, o conceito de capital social permanece surpreendentemente impreciso durante toda a exposição do capítulo final - pois Putnam jamais o define. Feita a alusão inicial ao capital social, tudo o que se segue é, inicialmente, uma remissão à exposição do conceito feita por James Coleman e outros autores, seguida por uma enumeração um tanto vaga de atributos do capital social, que jamais chega perto de uma definição. (REIS, 2003, p. 44).

No entanto, Reis (2003) não anula o brilhantismo existente no trabalho de Putnam (2002) e enumera um conjunto de virtudes que norteou os estudos deste autor por quase duas décadas, com destaque para os atributos ligados a "confiança", "desempenho institucional" e "capital social". Para Reis (2003), a noção de capital social surge como uma valiosa lente para compreender as sociedades modernas, permitindo a 
reestruturação e a modificação de certas práticas relacionadas, de um lado, às instituições, de outro, ao processo de formação político-cultural fundamentado em ações cívicas.

O capital social passou a ser considerado, então, de fundamental importância, além da consolidação da democracia, na realização de uma efetiva governança local e urbana, visando a sustentar redes de inovação tecnológica e de políticas públicas. Contribuiu ainda para o desenvolvimento comunitário e social via implementação de projetos de inclusão social e de combate à pobreza, bem como estimulou a proteção do meio ambiente e o uso sustentável dos recursos naturais (BRIGGS, 2004; BULLEN, 2000; COLEMAN, 1990; FUKUYAMA, 1995; NORTH, 1990; PORTES, 1998; PUTNAM, 2002).

O recorte teórico-metodológico e empírico delimitado por Putnam (2002), ao tratar da relação comunidadedemocracia na Itália moderna, revela um conjunto de elementos que se complementam e se afastam ao serem confrontados com a realidade pesquisada. Elementos como "desempenho institucional", "confiança", "civilidade", "ação coletiva" e "capital social" marcam a trajetória de sua linha de pensamento e evidenciam fatores que se desenvolvem tendo por base duas questões centrais: "Por que alguns governos democráticos têm bom desempenho e outros não?" e "O que entendemos por desempenho institucional?". São questões complexas e abrangentes, mas que permitem analisar o papel das instituições e a nossa própria condição humana no contexto da sociedade moderna. Portanto desempenho institucional pode ser entendido da seguinte maneira:

O conceito de desempenho institucional baseia-se num modelo bem simples de governança: demandas sociais $\Rightarrow$ interação política $\Rightarrow$ governo $\Rightarrow$ opção de política $\Rightarrow$ implementação. As instituições governamentais recebem subsídios do meio social e geram reações a esse meio. Pais que trabalham fora procuram creches acessíveis, comerciantes preocupam-se com furtos em suas lojas, veteranos de guerra execram a morte do patriotismo. Os partidos políticos e outros grupos articulam esses interesses, e as autoridades, quando muito, deliberam sobre o que fazer. Então, adota-se uma política (que pode ser apenas simbólica). A menos que essa política seja "nada a fazer", ela tem que ser implementada - criar novas creches (ou incentivar a iniciativa privada a fazê-lo), pôr mais guardas na ronda, hastear bandeiras com mais frequência. Para ter um bom desempenho, uma instituição democrática tem que ser ao mesmo tempo sensível e eficaz: sensível às demandas de seu eleitorado e eficaz na utilização de recursos limitados para atender a essas demandas. (PUTNAM, 2002, p. 24-25).

Nota-se, entretanto, a complexidade de fatores que condicionam o sucesso ou o fracasso do "desempenho institucional". São fatores que envolvem diversos atores e segmentos da sociedade civil organizada democraticamente e que, de certa maneira, repassam para os gestores públicos e políticos a missão de maximizar os recursos limitados em poder do Estado.

Assim, para além dos papéis exercidos pelo Estado na sociedade, observa-se que a relevância em se investigar a ação de uma perspectiva supraindividual deve-se à constatação de que ela é capaz de sintetizar e refletir significados e padrões comuns a uma coletividade. Embora condicionada pela singularidade, tem muito a dizer sobre os valores hegemônicos e as práticas institucionalizadas na sociedade. Algumas destas práticas e valores podem ser visualizados na Tabela 1, que mostra a interdependência existente entre capital social, estrutura e elementos cognitivos, presentes nas sociedades contemporâneas institucionalizadas. 
Tabela 1

Interdependência entre Capital Social, Estrutura e Cognição

\begin{tabular}{|l|l|l|}
\hline \multicolumn{1}{|c|}{ Capital Social } & \multicolumn{1}{|c|}{ Elementos Estruturais } & \multicolumn{1}{|c|}{ Elementos Cognitivos } \\
\hline Fontes & Redes e Relações & Normas \\
\hline Manifestações & $\begin{array}{l}\text { Interpessoais } \\
\text { Papéis e Regras } \\
\text { Procedimentos e } \\
\text { Precedentes }\end{array}$ & $\begin{array}{l}\text { Crenças } \\
\text { Atitudes } \\
\text { Valores }\end{array}$ \\
\hline Fatores Dinâmicos & $\begin{array}{l}\text { Organização Social } \\
\text { Ligações Horizontais e } \\
\text { Verticais }\end{array}$ & $\begin{array}{l}\text { Confiança } \\
\text { Cooperação }\end{array}$ \\
\hline Elemios & $\begin{array}{l}\text { Expectativas que levam ao comportamento cooperativo que geram } \\
\text { benefícios mútuos. }\end{array}$ \\
\hline
\end{tabular}

Fonte: Adaptado de Uphoff, 2000, p. 221.

Mediante os elementos acima expostos, nota-se que a ideia de capital social - presente em várias abordagens organizacionais - surge como organizadora da ação coletiva no institucionalismo, em que a noção de homo economicus se desenvolve atrelada à figura do indivíduo racional que age exclusivamente visando aos seus interesses. Putnam (2002) considera que o capital social é constituído por elementos (redes, normas e confiança) das organizações sociais que facilitam a ação e a cooperação para a aquisição de benefício mútuo, uma vez que a formação de um acervo abundante de capital social proporciona um trabalho em conjunto mais fácil de ser desenvolvido.

Confiança, normas, cadeias de relações sociais são tipos de capital social. O capital social facilita a cooperação espontânea e tal como sucede com o capital convencional, os que dispõem dele, tendem a acumular mais. O capital social multiplica-se com o uso e mingua com o desuso. Por esse motivo, a criação e dilapidação do capital social se caracterizam por círculos virtuosos e círculos viciosos. (PUTNAM, 2002, p.180).

Ao contribuir para tornar popular a noção de capital social, com base em seus estudos sobre a Itália moderna (1993) e sobre os Estados Unidos (2000), Putnam (2002) identifica-a como os traços da vida social, suas redes de relações, normas e confiança que facilitam a ação conjunta em prol de objetivos comuns. Conceitualmente esse autor define capital social como a capacidade de grupos e organizações que formam a sociedade civil desenvolverem trabalhos coletivos no alcance de objetivos comuns, possibilitadores de maior eficiência na produção coletiva de riqueza. Trata-se de um conceito, de acordo com os críticos da teoria de Putnam, impreciso em termos de definição, mas que nos oferece elementos importantes para o entendimento do capital social na atualidade, principalmente quando se trata de análises voltadas para as instituições públicas e representações políticas (BRIGGS, 2004; BULLEN, 2000; REIS, 2003). 
É possível, então, que a busca pela otimização, ou seja, pela maximização da diferença entre o benefício e o ônus determine o alinhamento entre fins e meios e coloque o capital social como subsidiário das ações coletivas. Embora seja um fato, a liberdade de ação é condicionada pela lógica instrumental. O mercado e as leis da economia neoclássica representam a materialização de tal racionalidade. Neste campo, a ação coletiva é marcada pela impessoalidade. A equivalência das trocas e a ausência da dívida tornam cada relação pontual e não instauram um sistema de obrigações capaz de inibir a exploração, a injustiça e a exclusão (COLEMAN, 1990; FREY, 2000).

No entanto, capital social pode ser compreendido como sinônimo da existência de confiança social, normas de reciprocidade, redes de engajamento cívico e, finalmente, de uma democracia saudável e vital. Assim, essas organizações básicas da vida social, como instituições de ensino, organizações jurídicas, sindicatos, associações comunitárias e profissionalizantes, entre outras formas de organizações cívicas, são essenciais para o estabelecimento de normas e padrões comuns, para a promoção de confiança social e interpessoal e, no final, para o crescimento do engajamento cívico. Para Putnam (2002), o capital social é um ativo importante individual e socialmente. As redes e os vínculos que nelas se dão entre pessoas têm um valor e são importantes para os indivíduos, os grupos e as comunidades. Assim, do mesmo modo que o capital físico e o capital humano podem aumentar a produtividade individual ou coletiva, os contatos sociais também podem afetar a produtividade do indivíduo e de grupos de indivíduos. Desse modo, o capital físico refere-se aos objetos físicos; o capital humano, às propriedades das pessoas; e o capital social, aos vínculos entre os indivíduos. Portanto, o capital social refere-se às características da organização social, que podem melhorar a eficiência da sociedade e do Estado e facilitar as ações coordenadas dos indivíduos.

Em um contexto como esse, será incumbência do governo atuar, por meio do monopólio do uso legítimo da força, como mediador em última instância dos acordos, costumes e valores oriundos da livre interação e cooperação - e, naturalmente, também dos conflitos - entre os indivíduos e grupos diversos na sociedade. Ele permanece, de qualquer maneira, sendo ator crucial para o funcionamento das instituições, isoladamente de longe o mais importante, poderosamente capaz de influenciá-las - para melhor ou pior - tanto no seu formato quanto no seu desempenho. Pois é somente ao constituir a forma legal que lhe permitirá desempenhar seu papel de fiador dos acordos firmados no interior da sociedade que o governo propriamente institucionaliza esses acordos; transforma acordos circunstanciais ou formas momentâneas de cooperação em instituições propriamente ditas. (REIS, 2003, p. $41)$.

Nesse contexto de diversidades de interesses, o Estado surge como organizador e regulador e, em certo ponto, fiscalizador das ações dos indivíduos na sociedade. Trata-se da contribuição do Estado na superação dos "dilemas da ação coletiva".

Contudo, uma reflexão conjunta e interligada, à luz do capital social, das teorias institucionalistas e da administração pública, objetiva elucidar as estruturas e o funcionamento das instituições no âmbito da vida social. Além disso, o corpo teórico em destaque pode contribuir para o entendimento da relação entre Estado e sociedade, tendo em vista os arranjos e as redes institucionais em desenvolvimento na atualidade, o que será visto na seção a seguir.

\section{Abordagem Institucionalista em Interface com o Capital Social}

A seção anterior priorizou discussões em torno dos defensores e críticos do capital social, possibilitando a identificação de dimensões e categorias importantes ao entendimento de tal temática. As categorias mais debatidas pelos teóricos do capital social são: desempenho institucional; confiança; participação cívica, cidadania e descentralização das decisões governamentais. Essas categorias refletem os elementos 
necessários para se garantir relativa "harmonia social", seja em um grupo, instituição, comunidade, município ou nação. São elementos que contribuem para melhor compreender a relação social existente entre indivíduos e, ou, instituições em contextos sociais complexos e abrangentes. Assim, as categorias discutidas no âmbito da literatura sobre capital social vão ao encontro daquelas levantadas pelos teóricos do institucionalismo, principalmente em se tratando de assuntos que procuram relacionar instituições e políticas públicas.

No institucionalismo sobressaem as questões voltadas ao entendimento de normas e regras estatuídas institucionalmente, aspectos ambientais, grau de cooperação entre os indivíduos e as instituições, sistemas formais de organização, legitimidade institucional, bem como a capacidade das instituições de se articular em redes. Tanto no capital social quanto no institucionalismo, procura-se compreender os elementos que estruturam e dão forma às instituições da atualidade. Propõe-se ainda a entender como as instituições desempenham suas funções no contexto social.

O institucionalismo concebido no âmbito da Teoria das Organizações permite o confrontamento teóricoconceitual entre perspectivas "tradicionais" e "modernas" advindas de propostas voltadas à compreensão das instituições no meio social. Dessa confrontação de ideias e perspectivas teóricas, surgem novas formas de organização dentro das instituições. Portanto o institucionalismo passou a investigar "modelos teóricos institucionais" capazes de promover a substituição de elementos técnicos por elementos ligados aos valores (principalmente os relacionados aos aspectos culturais) que, consequentemente, seriam determinantes no desenvolvimento das atividades institucionais (BOWRING, 2000; BRYMAN, 1984; DIMAGGIO, 1991; HASSARD, 1993; MACHADO-DA-SILVA e GONÇALVES, 2000; MORGAN, 1980; SCOTT, 1995).

A Tabela 2 apresenta um panorama sintético das principais perspectivas teórico-conceituais polarizantes que vêm acompanhando a Teoria Institucional no contexto das transformações e das principais tendências nos estudos sobre as instituições modernas.

Tabela 2

Perspectivas teórico-conceituais polarizantes da Teoria Institucional

\begin{tabular}{|c|c|}
\hline Perspectivas Clássicas & Perspectivas Modernas \\
\hline Abordagem funcionalista & Abordagem interpretativa/(des)construção \\
\hline Velho institucionalismo & Neo-institucionalismo \\
\hline Ambientes técnicos e institucionais & Esquemas interpretativos e cognição \\
\hline Atores organizacionais passivos & Atores organizacionais criativos e proativos \\
\hline Estímulo-resposta & Estímulo-interpretação-resposta \\
\hline $\begin{array}{l}\text { Pressão ambiental para conformidade das } \\
\text { organizações }\end{array}$ & $\begin{array}{l}\text { Pressões das organizações sobre condições ambientais para } \\
\text { atingir objetivos e manter interesses }\end{array}$ \\
\hline $\begin{array}{l}\text { Mudança de ambiente: adaptação de indivíduo } \\
\text { e organização }\end{array}$ & Indivíduos e organização mudam ambiente \\
\hline Isomorfismo coercitivo & Isomorfismo cognitivo (mimético) e normativo \\
\hline
\end{tabular}




\begin{tabular}{|l|l|}
\hline Administração empresarial por tarefas & Administração empresarial por competências \\
\hline Administração pública tradicional e burocrática & Administração pública gerencial e "societal" \\
\hline Cultura nacional & Cultura organizacional \\
\hline Regimes autoritários e patrimonialistas & Regimes democráticos e concorrenciais \\
\hline
\end{tabular}

Fonte: Dados de pesquisa bibliográfica, 2010.

Os elementos contidos na tabela acima expressam um conjunto de encaminhamentos teórico-conceituais que objetivam modificar, reestruturar e adaptar as instituições, de maneira geral, às tendências organizacionais e gerenciais da atualidade. Não se trata de rompimentos drásticos e definitivos entre as "tradicionais" e as "modernas" orientações organizacionais, mas tão somente de propostas teórico-conceituais alternativas para (re)organizar as instituições.

Assim, os debates que vêm ocorrendo no interior do institucionalismo permitem construir elos de aproximação entre as diversas abordagens discutidas e selecionadas neste estudo, desde a predominância do paradigma funcionalista nos estudos organizacionais, passando pela marcante presença da burocracia nas instituições modernas e relevância dos aspectos culturais, até a importância das práticas cognitivas entre e intrainstituições (CASEY, 2004; MORGAN, 1980). Esta relação aponta o quanto a teoria das organizações é marcada pela multiplicidade de enfoques e abordagens que ora se preocupam em oferecer uma interpretação mais aprofundada da realidade institucional, ora privilegiam a busca de respostas mais adequadas frente às exigências ambientais.

Empregando o termo 'instituição' em sentido amplo para designar 'as regras do jogo numa sociedade', North assinala que os modelos institucionais tendem a auto-reforçar-se, mesmo quando são socialmente ineficientes. Primeiro, quase sempre é mais fácil para um agente individual adaptar-se às regras do jogo vigentes do que tentar modificá-las. Na verdade, tais regras costumam induzir à formação de organizações e grupos interessados em suas imperfeições. Segundo, depois que o desenvolvimento toma determinado rumo, a cultura organizacional, os costumes e os modelos mentais do mundo social reforçam essa trajetória. A cooperação ou a omissão e a exploração tornam-se entranhadas. As regras informais e a cultura não só mudam mais lentamente do que as regras formais, como tendem a remodelálas, de modo que a imposição externa de um conjunto comum de regras formais acarreta resultados amplamente divergentes. (PUTNAM, 2002, p. 189).

A definição do termo "instituição" e a exposição de elementos como cultura, formalidade/informalidade, cooperação/omissão demonstram a complexidade de regras a serem consideradas no processo de institucionalização das organizações. Trata-se de visões contingenciais das organizações que se formam e se desagregam no contexto das sociedades modernas.

$\mathrm{O}$ amadurecimento dos debates travados pela ciência administrativa proporcionou, entre tantas outras perspectivas, a consideração das instituições mediante uma abordagem contingencial, o que implica vê-las inseridas em um ambiente onde sofrem e provocam mudanças tanto interna quanto externamente. A ênfase no ambiente é a principal contribuição da escola institucional, que coloca no centro de sua interpretação a realidade organizacional, a legitimidade e o isomorfismo como fatores vitais para sua sobrevivência (MACHADO-DA-SILVA e GONÇALVES, 2000). 
De acordo com North (1990), a busca por legitimidade envolve um processo de institucionalização que pode se dar por meio dos seguintes estágios: habitualização, objetificação e sedimentação. Apesar do tratamento estático dado, eles demonstram ser necessários à institucionalização propriamente dita. Assim, o processo de institucionalização inicia-se - habitualização - em virtude de necessidades e pressões do contexto (mudanças tecnológicas, legislação e forças de mercado) por inovação. Segundo North (1990), em consequência do monitoramento que a organização faz dos competidores e de esforços para aumentar sua competitividade relativa, a organização se movimenta em direção a um status mais permanente e disseminado - objetificação. Por fim, a institucionalização total se dá pela propagação, virtualmente completa, de suas estruturas por todo o grupo de atores, como pela perpetuação de estruturas de um período de tempo consideravelmente longo sedimentação. North (1990) destaca que este processo de adaptação às mudanças leva a estrutura organizacional a mudar continuamente a partir do momento que normas, regras e padrões institucionalizados não garantem mais a redução da incerteza presente no ambiente. Assim, continuamente, há um processo de formação, desinstitucionalização, institucionalização e reinstitucionalização, ou seja, estados que oscilam dinamicamente da ordem à desordem, da construção à desconstrução, em busca de um padrão social estabilizado ou pelo menos aceitável (BRYMAN, 1984; NORTH, 1990).

Assim, de acordo com Bryman (1984), o processo de institucionalização, por sua vez, pode apoiar-se nos pilares regulativo, normativo ou cognitivo. No pilar regulativo, regras e leis são formuladas e legitimadas para controlar os empregados, cujas ações indesejadas são alvo de sanção e coerção. No normativo, determinam-se os comportamentos desejados que, após contínua repetição, são interiorizados, levando à legitimação. Já o pilar cognitivo dá importância à dimensão subjetiva, na qual os conhecimentos são compartilhados de forma que acabem por ser legitimados.

No entanto, Bowring (2000) adverte que esta busca por legitimidade está relacionada às pressões ambientais continuadas que as organizações sofrem no sentido de torná-las mais homogêneas em termos estruturais e processuais. Esta pressão por homogeneidade organizacional, por seu turno, decorre de mecanismos institucionais coercitivos, miméticos e normativos. No primeiro caso, uma organização exerce pressões sobre outras que dela dependem. O mimetismo ocorre quando uma organização adota estruturas e procedimentos de outra devido às incertezas tecnológicas ou objetivos ambientais, semelhante a um processo de imitação das práticas organizacionais que deram certo. O mecanismo normativo ocorre quando um conjunto de normas e métodos é adotado pelas organizações, principalmente do mesmo setor. Um dos principais instrumentos normativos é a profissionalização, que determina quais são as normas, regras, procedimentos e rotinas de trabalho de cada cargo ou função desempenhada.

Vale salientar, segundo Dimaggio (1991), que os mecanismos isomórficos devem variar a depender do contexto de cada sociedade, apesar do consenso - que parece existir na literatura internacional - de que os mecanismos normativo e mimético são suficientes no processo de mudança organizacional, ou seja, na promoção da institucionalização. Em sociedades com forte tradição democrática e com alto nível de competição, por exemplo, a tendência é de que predominem os mecanismos miméticos e normativos de pressão para a estabilidade e a mudança organizacional (BOWRING, 2000; BRYMAN, 1984; DIMAGGIO, 1991). Entretanto, no caso brasileiro, de acordo com Machado-da-Silva e Gonçalves (2000), estudos revelam que o mecanismo coercitivo como instrumento de manutenção da ordem e, paradoxalmente, de transformação social é legitimado pelo formalismo. Isto acontece porque, para nós brasileiros, que somos fortemente influenciados por padrões e modelos estrangeiros, é mais fácil adotar uma estrutura formal por decreto ou lei do que institucionalizar o correspondente comportamento social e, ou, organizacional. Ou seja, na análise do processo de formação sociocultural da sociedade brasileira, não se caminhou do costume para a teoria, do vivido para o formal, mas do teórico para o costume, do formal para o vivido (TOLBERT e ZUCKER, 2006). Portanto configurou-se uma espécie de formalismo funcional como uma estratégia de construção nacional.

O que se pôde verificar é que, apesar de existirem três orientações distintas (econômica, política e sociológica), quando se discute o tema institucionalização, a maioria dos estudiosos da área focaliza sua 
análise de acordo com a orientação sociológica que teve grande contribuição de Durkheim e Weber (MORGAN, 1980). Essas três orientações agregam em suas formulações os conceitos e ideias do "novo" e do "velho" institucionalismo, ou de perspectivas "modernas" e "pós-modernas" (BOWRING, 2000; MORGAN, 1980; NEE, 1998; TOLBERT e ZUCKER, 2006).

Os novos institucionalistas divergem entre si com relação a muitos pontos, tanto teóricos quanto metodológicos. Mas estão de acordo em dois pontos fundamentais: $1^{\circ}$ ) As instituições moldam a política. As normas e os procedimentos operacionais típicos que compõem as instituições deixam sua marca nos resultados políticos na medida em que estruturam o comportamento político. Os resultados não podem ser meramente reduzidos à interação de jogo de bilhar dos indivíduos nem à interseção das forças sociais gerais. As instituições influenciam os resultados porque moldam a identidade, o poder e a estratégia dos atores. $2^{\circ}$ ) As instituições são moldadas pela história. Independentemente de outros fatores que possam influenciar a sua forma, as instituições têm inércia e 'robustez'. Portanto corporificam trajetórias históricas e momentos decisivos. A história é importante porque segue uma trajetória: o que ocorre antes (mesmo que tenha sido de certo modo 'acidental') condiciona o que ocorre depois. Os indivíduos podem 'escolher' suas instituições, mas não o fazem em circunstâncias que eles mesmos criaram, e suas escolhas por sua vez influenciam as regras dentro das quais seus sucessores fazem suas escolhas. (PUTNAM, 2002, p. 23).

Por exemplo, o "velho" modelo institucional buscava interpretar as organizações como uma expressão estrutural da ação racional que, ao longo do tempo, são sujeitas às pressões do ambiente social e, ou, organizacional e transformam-se em sistemas orgânicos. Os valores substituem os fatores técnicos na determinação de tarefas organizativas. Já os "novos" institucionalistas buscaram uma abordagem com maior poder explicativo da realidade organizacional ao interpretar a estrutura como resultado de concepções culturalmente construídas em uma dualidade que envolve tanto as relações que se estabelecem no interior das organizações, como as que têm origem no ambiente. Ou, ainda, o "novo" institucionalismo se propôs a romper com o caráter positivista e com o paradigma funcionalista dominante presente no "velho" institucionalismo, apoiando-se em uma perspectiva mais cognitiva e embasada no paradigma interpretativo.

Para March e Olsen (1989) e Hall e Taylor (2003), os dilemas institucionais seriam absorvidos pelas instituições, não necessariamente porque aumentariam sua eficácia em termos de fins e meios, mas principalmente em consequência do mesmo tipo de processo de transmissão que dá origem às práticas organizacionais no âmbito das instituições modernas. Ao longo deste processo, as instituições poderiam adotar formas e práticas institucionais compatíveis com seus propósitos e objetivos, já que possuem reconhecimento em termos de legitimidade social.

Há, contudo, os que defendem não haver, basicamente, diferença entre o "novo" e o "velho" institucionalismo. Segundo os defensores desta ideia a diferenciação acontece em virtude de certa "confusão paradigmática" presente na nova corrente. Afirmam ainda que esta confusão é gerada por uma divergência interna daqueles que se autodenominam neoinstitucionalistas por não atenderem aos microfundamentos oficiais desta nova abordagem (baseada no construtivismo social e na etnometodologia). Esta incoerência interna leva o "novo" institucionalismo a não se distanciar totalmente da ortodoxia positivista-funcionalista dos estudos organizacionais (BRUSCO, 1990).

Tal discussão acaba por revelar que a própria teoria institucional está em processo de institucionalização no âmbito dos estudos organizacionais, ou ainda que está na sua fase latente, tentando construir-se ou pelo menos consolidar-se enquanto teoria organizacional. $\mathrm{O}$ que reforça este pressuposto é o fato de que tem aumentado o número de investigações sobre a temática em diferentes ramos das ciências sociais e suas contribuições são inegáveis, principalmente com relação ao isomorfismo e à legitimidade das instituições. 
Uma dessas investigações sobre a temática "institucionalismo" refere-se à compreensão das estruturas e das funcionalidades inerentes à administração pública, objeto de análise da próxima seção.

\section{Administração Pública}

A administração, de modo geral, e a administração pública, de modo particular, encontram-se ligadas à teoria geral da administração e aos estudos organizacionais. A natureza do conhecimento em administração no âmbito público é um tema amplamente discutido nos dias atuais e retrata casos de particularidades existentes tanto em países desenvolvidos quanto em países em processo de desenvolvimento. Outro fator importante da esfera de análise pública da administração vai ao encontro de formas de gestão e modelos de culturas organizacionais debatidos no seio da administração pública (ABRÚCIO, 1998; BRESSER-PEREIRA, 2005; FRANÇA FILHO, 2004; PAULA, 2005).

A administração moderna evidencia três abordagens teóricas abrangentes. Primeiro, com os pioneiros da administração científica, houve um direcionamento excessivo em relação ao conhecimento sobre os instrumentos e as técnicas gerenciais, que se configuraram como um sistema de normas e procedimentos para acompanhar atividades de trabalho tais como distribuição de tarefas e especialização das funções e cargos administrativos. Esses procedimentos e normas eram pensados tendo por base "modelos conceituais gerenciais" que incorporavam ideias sobre gestão e possuíam a pretensão de uma validade universal de seus pressupostos, podendo ser aplicados tanto em organizações privadas quanto públicas. Para França Filho (2004) e Paula (2005), os modelos conceituais de orientação gerencialista dão ênfase, principalmente, aos processos de eficácia e de eficiência administrativa, o que demonstra que poderiam ser considerados universais. Observe-se que a ênfase, neste caso, está na racionalidade e nos objetivos pretendidos, o que coloca em cheque aspectos importantes relacionados a questões ético-morais e à prática da aprendizagem organizacional.

Em seguida, houve a disseminação das ideias ligadas às áreas funcionais da administração (principalmente finanças, marketing, pessoas e produção), todas inspiradas nas premissas da Escola Clássica da Administração, tendo na divisão social do trabalho o ponto de partida para a modificação das estruturas, arranjos e tendências organizacionais. Este segundo momento simboliza o advento de especializações diversificadas da prática administrativa e contribuiu para que o próprio sentido da administração na atualidade passasse de percepções generalistas para percepções específicas da "arte de administrar" (DRUCKER, 1999; FRANÇA FILHO, 2004; PAULA, 2005).

A terceira grande orientação da administração moderna corresponde aos debates suscitados no seio dos estudos organizacionais. Esta área de estudo da administração redireciona o foco da gestão para a organização como unidade de análise. Nesta fase, estudiosos das organizações atribuem a Chester Barnard o relevante papel de apresentar a organização como algo essencial e que deveria ser estudada com grande atenção, pois tratar das questões referentes às práticas gerenciais sem a relevante consideração do seu espaço social ou organizacional de atuação poderia acarretar, no mínimo, uma ausência comprometedora da qualidade dos estudos direcionados para este campo da administração (DRUCKER, 1999). Assim, as bases fundamentais dos estudos organizacionais encontram-se intimamente ligadas a duas categorias abrangentes de análise, quais sejam: o "enfoque comportamental" derivado da ampla influência dos psicólogos norteamericanos nas organizações; e o "enfoque sistêmico", oriundo da biologia, que contribuiu para melhor compreender as organizações de modo holístico (BRYMAN, 1984; BURRELL e MORGAN, 1979).

Nesse contexto não se pode desconsiderar ou negar o importante papel que a ciência da administração possui no processo de compreensão e análise das organizações modernas. Mesmo não havendo consenso entre os estudiosos da área, espera-se que o campo de estudos organizacionais possa criar as necessárias condições em prol da promoção de ambientes cada vez mais inter e multidisciplinares, tendo por objetivo consolidar a 
administração como um importante e promissor campo científico e, como pano de fundo, os desafios e tendências globalizantes atuais, o que inclui a administração pública brasileira.

No Brasil, ao longo de sua evolução histórica, os estudos sobre a administração pública envolveram sempre elementos diversificados e dimensões herdadas das crenças e práticas advindas da formação sociopolítica e cultural do país. Esses elementos e dimensões têm se manifestado em traços característicos que prevalecem até os dias atuais na maneira de gerir e de se apropriar do aparato público institucional (LANNA, 1995; LEAL, 1993; FAORO, 2000; HOLANDA, 2000; NUNES, 1997).

Assim, da confrontação literária observa-se que a administração pública no Brasil é marcada pelo hibridismo nas relações entre Estado e sociedade, ou seja, existe a convivência de diversos tipos de práticas como o nepotismo, a corrupção, o personalismo, o clientelismo, o corporativismo e o insulamento burocrático, que, juntos, contribuem para alavancar as mazelas políticas existentes nos espaços institucionais de domínio público. Paralelamente, a trajetória histórica da administração pública brasileira revela três modelos marcantes da organização pública das instituições brasileiras (nos níveis federal, distrital, estadual e municipal), sendo eles o patrimonialismo, o burocratismo e o gerencialismo.

\section{Raízes do Estado patrimonialista no Brasil}

A literatura clássica existente no Brasil referente à administração pública destaca que a relação entre Estado e administração pública possui sua raiz no desenvolvimento das práticas patrimonialistas ocorridas desde o período colonial mediante a supremacia de Portugal sobre o Brasil (FAORO, 2000; HOLANDA, 2000; LANNA, 1995; LEAL, 1993). As marcas deste período vão fomentar as atitudes políticas e as formas de gerenciamento da "coisa pública" expressas, principalmente, nas práticas administrativas e estamentais.

O modelo patrimonialista formalizado nas ações e práticas políticas no Brasil permeou e ainda permeia as relações sociais, fere a Constituição e legitima atitudes e costumes advindos das relações de poder e dominação encontradas em nossa estrutura política e no aparato da administração pública. Este mesmo modelo ainda se mantém arraigado na esfera política atual, principalmente no interior do país e em regiões como o Nordeste brasileiro, em que a dependência da "máquina pública" se tornou cultural, e esta é mediada pela defesa de interesses particularizados.

A questão fundamental que parece surgir dessa brevíssima discussão é: qual a natureza específica da hierarquia no Nordeste brasileiro? A comparação entre costa e sertão aparecerá aqui como pano de fundo desta que será a questão fundamental desse trabalho. Como foi dito, veremos que a hierarquia no Nordeste não exclui, mas pressupõe violência e arbitrariedade, e ao mesmo tempo se nutre das relações de classe. Esse trabalho pretende demonstrar a possibilidade da existência de uma síntese entre hierarquia, violência e relações de classe, mas sua ênfase recairá no primeiro desses termos. Veremos que categorias como "respeito" fundam relações estruturais, mesmo num contexto cada vez mais impessoal; isso não exclui que, ao mesmo tempo, a arbitrariedade do patrão possa também contribuir, em grande medida, para a constituição da realidade social. (LANNA, 1995, p. 46).

Com o advento da República, as elites agrárias assumiram o poder e constituíram por mais de três décadas a chamada República Oligárquica (1894-1930). Segundo Faoro (2000, p. 243), a transição do regime monárquico imperial para o republicano "[...] irá acentuar e exacerbar a função eleitoral do coronel. Tirarlhe-á as albardas centrais não para autonomizá-lo, mas para entregá-lo aos poderes estaduais e federal. Esta transição está na essência dos acontecimentos que partem do 15 de Novembro de 1889". A partir de então, 
esse cenário político da história do Brasil tornou-se solo fértil para a proliferação de ações de "mandos" e "desmandos", caracterizando ainda mais o Estado Patrimonial. O fenômeno denominado Coronelismo foi o retorno ao poder dos fazendeiros que detinham o controle político e econômico no meio rural desde os tempos da monarquia. Lanna (1995), Faoro (2000) e Holanda (2000), em suas análises sobre o patrimonialismo, afirmam que, desde a colonização do Brasil pelos portugueses, os fazendeiros, conhecidos por "coronéis", sempre detiveram prestígio social, ora assumindo o poder diretamente em certas localidades, ora se opondo aos governantes que tentavam interferir em suas "terras" e "redutos" políticos, como foi, a título de exemplo, a disputa entre os partidos políticos conservadores e liberais que abrigavam os "coronéis", entendidos aqui como grandes fazendeiros e políticos influentes, principalmente no período regencial e início do "Brasil República".

Para Leal (1993), a história brasileira ocorrida entre os séculos XIX e início do XX revela que no âmbito rural, o coronel era um "bem amado". A sua "clientela" - isto é, a imensa maioria de camponeses miseráveis que dele dependiam, giravam ao seu redor e dispunham de seus favores - lhe devotava absoluta fidelidade. Para ter a devoção de seus clientes, o coronel lhes cedia partes de suas terras para a sua subsistência, ajudava-os nas doenças, com médicos e remédios, e lhes garantia proteção nos problemas com a polícia e, por vezes, com a justiça. Em troca, essa "clientela" era forçada a votar nos candidatos que ele apoiava. Diversos autores detiveram-se em entender a gênese e as práticas do coronelismo, buscando elucidar suas ações de poder e dominação. Neste caso, observa-se que o habitat dos fazendeiros que detinham o poder eram os:

[...] municípios do interior, o que equivale a dizer os municípios rurais, ou predominantemente rurais; sua vitalidade é inversamente proporcional ao desenvolvimento das atividades urbanas, como sejam o comércio e a indústria. Conseqüentemente, o isolamento é fator importante na formação e manutenção do fenômeno. (LEAL, 1993, p. 251).

De outro enfoque, Lanna (1995), ao analisar o coronelismo no Nordeste brasileiro, observou que dois são os elementos fundamentais que ainda mantêm viva a chama deste fenômeno secular: as práticas comuns entre as relações de patronagem e compadrio, dando forma e legitimidade à figura do "coronel", que produz ou reproduz, no interior da comunidade, sua autoridade e controle. Tanto os laços de patronagem como os de compadrio são vistos como formadores de comunidades nas quais as pessoas se aproximam ora para prestar serviço ao fazendeiro, ora para convidá-lo a apadrinhar seus filhos, o que, na maioria das vezes, acarreta trocas recíprocas de "favores", gerando uma nova relação, qual seja, a de clientelismo, como observou Lanna (1995). Esses valores e práticas também encontram-se presentes em muitas de nossas instituições como forma de perpetuar o poder e a dominação sobre os demais indivíduos. Elementos como o clientelismo, prática comum entre os políticos da "elite agrária brasileira", contribuíram significativamente na configuração hierárquica de diversas instituições de nosso país e disseminaram as tradições patrimonialistas ao longo da história da República.

Essas práticas contribuíam para alavancar os princípios ligados ao patrimonialismo, ou seja, com base em uma interpretação weberiana do assunto, prevaleciam a tradição e os costumes em detrimento da impessoalidade da lei e do profissionalismo administrativo institucionalizado. Nesse caso, Weber (1999) chama de "tipos ideais" as modalidades de "dominação" por ele concebidas. Elas apresentam-se sob os seguintes "tipos ideais": "tradicional ou patrimonial", "legal ou racional burocrático" e "carismático". As duas primeiras (patrimonial e burocrática) serão discutidas e analisadas neste estudo.

No tipo de "dominação tradicional ou patriarcal" sobressaem os laços de submissão, ela é marcada por relações de "patriarcalismo", em que prevalecem valores como a honra, a amizade, o parentesco, o protecionismo e a reprodução da tradição entre dominantes e dominados. A obediência ao "outro" desenvolve-se por meio do respeito a toda uma "tradição", em que o dominante é visto como possuidor de "valores superiores", detentor do "dom da graça" ou pela relação de "servidão" e "interesses pessoais", na 
qual o ser dominado se encontrará sempre em posição de dependência em relação ao dominante, pois este último lhe oferece abrigo e proteção, mantendo para com aquele um caráter de fidelidade e obediência irrestrita. Desse modo, a relação de dominação apresenta características determinantes, "o conteúdo das ordens está fixado pela tradição, cuja violação desconsiderada por parte do senhor poria em perigo a legitimidade do seu próprio domínio, que repousa exclusivamente na santidade delas" (WEBER, 1999, p. 131). Nesse tipo de dominação, valores que acarretam posições de controle e autoritarismo são fundamentais para legitimar e institucionalizar o poder de dominação e autoridade entre os envolvidos.

Segundo Weber (1999), a manutenção e a garantia do poder da dominação tradicional (patrimonial) vêm da crença no passado eterno, na justiça e na pertinência da maneira tradicional de agir. O chefe de Estado tradicional é o senhor, que mantém seu poder e controle sobre seus súditos em detrimento da sua posição de sucessor, de uma relação de poder que lhe é transmitida, ao longo do tempo, por gerações passadas e que possuem a mesma coesão grupal de crenças e valores. Apesar de suas ordens possuírem um caráter personificado e arbitrário, sua área de abrangência é garantida pelos costumes e hábitos, e seus súditos o obedecem por respeito à sua posição tradicional ou pela coação.

À medida que os ideais e princípios de organização democrática passam a fazer parte da esfera pública e da sociedade brasileira, novos modelos de gestão da "máquina pública" começam a se fazer presente em detrimento da manutenção e continuidade do patrimonialismo. Um desses novos modelos refere-se à burocracia, que será mais bem discutida adiante. Assim, pelas análises e inferências feitas por BresserPereira (2005), nota-se que a adoção da burocracia no espaço público, para além de significar uma quebra de paradigmas, simbolizou um importante instrumento de combate aos elementos ligados ao patrimonialismo, como o nepotismo, o clientelismo, o mandonismo e a corrupção, contribuindo, mesmo que em passos lentos, para a proteção do bem público e encampando lutas pontuais contra a privatização do patrimônio estatal. Esse cenário impôs à administração pública a necessidade de desenvolver um tipo de administração que vislumbrasse distinguir o "espaço político" do "espaço de atuação do administrador público", mas também implementou ações que permitiram separar o "privado" do "público".

\section{Contribuições da burocracia para a administração pública no Brasil}

Historicamente a burocracia começou a fazer parte da esfera pública no Brasil quando o mundo se reorganizava dos traumas da primeira grande guerra mundial. Em 1933, foi criado pelo governo de Getúlio Vargas, o Departamento Administrativo do Serviço Público (DASP). Este, como órgão público, foi considerado um importante instrumento de difusão dos ideais da burocracia no Brasil.

Em 1933 foi criado o Departamento de Administração do Serviço Público (Dasp), que se transformou no símbolo da busca de um Estado moderno e de uma burocracia pública profissionalizada. Do ponto de vista prático, o departamento foi responsável pela organização do Estado quanto ao planejamento, orçamento e administração de pessoal. Entre 1945 e o golpe de 1964, ocorreram várias tentativas de se retomar a reforma com o mesmo ímpeto inicial, fortalecendo o sistema de mérito, a profissionalização dos burocratas e a organização do Estado. (PAULA, 2005, p. 106).

Sua principal função de acordo com as análises feitas por Bresser-Pereira (2005) era a de ser um agente modernizador dos processos administrativos, de acordo com as orientações dos princípios burocráticos de organização, promovendo mudanças significativas no aparato estatal brasileiro.

Para Weber (1999, p. 128), a "dominação racional legal" consiste em um modelo de organização burocrática, pois "qualquer direito pode ser criado e modificado mediante um estatuto sancionado corretamente quanto à 
forma". Neste caso, a relação entre dominantes e dominados reduz-se a uma formalidade legal preestabelecida, em que as ações desenvolvidas são amparadas por um "contrato" ou "leis" que regulamentam e orientam todo o processo de dominação burocrática.

O processo de organização do poder burocrático, que garante a sua legitimidade, provém de normas legais estatutariamente definidas em bases racionais e impostas em equivalência de igualdade a todos. Na dominação burocrática, a observância da justiça da lei é o pano de fundo de sua legitimação. As pessoas obedecem às leis e não à pessoa propriamente dita, como nas dominações tradicional e carismática, porque acreditam que as leis são constituídas e elaboradas por um procedimento escolhido tanto pelos subordinados quanto pelos dirigentes. Além disso, nesse tipo de cenário o dirigente é visto como uma pessoa que alcançou tal posição exclusivamente por procedimentos legais, via promoção, nomeação, progressão automática de cargos, concursos, entre outros, e é em consequência da posição conquistada que ele exerce o poder dentro das áreas preestabelecidas estatutariamente pelas regras e regulamentos sancionados legalmente.

Ao analisar o pensamento weberiano sobre a burocracia, Bresser-Pereira (2005) enumera um conjunto de princípios que irão dar forma e visibilidade à então moderna forma de organizar o espaço público. Neste momento a administração burocrática passa a ser pensada e praticada de acordo com as seguintes orientações: formalização das funções e atividades administrativas; unidade de comando fundamentada na organização hierárquica das instituições; centralização de poder via processo decisório; profissionalismo por meio do desenvolvimento de competências e habilidades administrativas; impessoalidade nas formas de tratamento da gestão pública; configuração organizacional pautada na estrutura piramidal de cargos e funções; estabelecimento de rotinas pouco flexíveis; normas e regras de controle atreladas aos processos administrativos; e foco em uma burocracia de Estado constituída por administradores profissionais, preferencialmente isentos das tramas e seduções políticas.

Foi um grande progresso o surgimento, no século XIX, de uma administração pública burocrática em substituição às formas patrimonialistas de administrar o Estado. Weber (1922), o principal analista desse processo, destacou com muita ênfase a superioridade da autoridade racional-legal sobre o poder patrimonialista. Apesar disso, quando, no século XX, o Estado ampliou seu papel social e econômico, a estratégia básica adotada pela administração pública burocrática - o controle hierárquico e formalista dos procedimentos - provou ser inadequada. Essa estratégia podia talvez evitar a corrupção e o nepotismo, mas era lenta, cara, ineficiente. Ela fazia sentido no tempo do Estado liberal do século XVIII: um Estado pequeno e dedicado à proteção dos direitos de propriedade; um Estado que só precisava de um Parlamento para definir as leis, de um sistema judiciário e policial para fazer cumpri-las, de forças armadas para proteger o país do inimigo externo, e de um ministro das finanças para arrecadar impostos. Mas era uma estratégia que já não fazia sentido, uma vez que o Estado havia acrescentado às suas funções o papel de provedor de educação pública, de saúde pública, de cultura pública, de seguridade social, de incentivos à ciência e à tecnologia, de investimentos em infra-estrutura, de proteção ao meio ambiente. Agora, ao invés de três ou quatro ministros, era preciso ter 15 ou 20. Ao invés de uma carga de impostos correspondente a $10 \%$ do PIB, necessitava-se de impostos que representavam de 30 a $60 \%$ do PIB. Ao invés da velha administração pública burocrática, uma nova forma de administração, que tomou de empréstimo os imensos avanços por que passaram, no século XX, as empresas de administração de negócios, sem contudo perder a característica específica que a faz ser administração pública: uma administração que não visa ao lucro, mas à satisfação do interesse público. (BRESSER-PEREIRA, 2005, p. 26-27).

Apesar das fragilidades e dos limites do modelo burocrático analisado por Bresser-Pereira (2005) no âmbito público, pode-se observar que o conceito de burocracia weberiano tinha no princípio da eficiência um porto seguro para planejar, organizar, executar e controlar as funções administrativas praticadas na administração 
pública. Assim, procurava-se com a administração pública burocrática gerar ambientes favoráveis à meritocracia, competência, ao profissionalismo e à formalização das relações de trabalho. Com todo este histórico de "boas intenções", o modelo burocrático se mostrou insuficiente para acompanhar as mudanças globais e a acentuada complexidade do Estado, dando espaço ao surgimento de novos modelos, como é o caso do modelo gerencialista.

\section{Aspectos da administração pública gerencial}

Em virtude de fragilidades e disfunções apresentadas tanto pelo modelo patrimonialista quanto pelo modelo burocrático no âmbito da administração pública, novas formas de gestão na esfera pública ganham vigor e força. Como forma de gestão emergente, surge no interior das discussões públicas tendências organizacionais voltadas ao gerencialismo, prática muito difundida nas empresas privadas e que obteve certa atenção da iniciativa pública a partir da década de 70 do século passado, tendo, principalmente nos Estados Unidos e na Inglaterra, condições e apoios necessários para a sua difusão.

Nesse contexto de desafios e adversidades, o neoliberalismo foi considerado a alternativa mais plausível para superar as vulnerabilidades ocasionadas pela crise mundial e serviu como instrumento orientador para garantir a governabilidade nas nações em que o modelo de administração pública gerencial se tornou hegemônico no contexto do capitalismo contemporâneo. Neste caso, destaca Abrúcio (1998), a ideologia neoliberal vislumbrava desenvolver no âmbito da administração pública a noção de "Estado mínimo" apresentando as seguintes características centrais para a sua consolidação: menor interferência do Estado nas questões econômicas; foco na eficiência e na efetividade dos setores públicos prestadores de serviços e produtores de bens para a sociedade; privatizações de setores públicos considerados impróprios para a responsabilidade estatal; descentralização das políticas públicas; garantia e manutenção do livre comércio; enxugamento da máquina pública; reforma ampla e profunda do Estado; utilização de técnicas e instrumentos gerenciais nos moldes da iniciativa privada.

O conjunto de orientações apresentado mostra a necessidade da realização de profundas mudanças no contexto da administração pública e aponta para a realização de reformas no Estado por meio de novas diretrizes de mercado, que afetam também as "empresas estatais". Para Bresser-Pereira (2005), essa nova realidade obriga os governos das nações democráticas a reverem as práticas administrativas no âmbito da administração pública, sinalizando diretrizes de uma reforma profunda no espaço público.

As novas diretrizes alinhadas ao modelo de administração pública gerencial vão marcar a difusão de ferramentas gerenciais, como privatização, terceirização, reengenharia, benchmarking, Programa de Demissão Voluntária (PDV), ajuste fiscal mais rigoroso, etc. Essas novas diretrizes marcam o início do primeiro mandato do presidente Fernando Henrique Cardoso e inauguram a formação do Ministério da Administração e Reforma do Estado (MARE), tendo, como ministro da pasta, Luís Carlos Bresser-Pereira, encarregado de elaborar e implementar as reformas que o Estado necessitava.

Concomitantemente aos acontecimentos de transformação da gestão pública no Brasil, observa-se, por parte do governo federal, a necessidade de descentralização administrativa do Estado. Nesse mesmo período, segunda metade da década de 90, ocorreu a constituição da chamada "administração indireta", que passou a conceder aos governantes estaduais e municipais maior autonomia para gerir os recursos regionais e locais.

No decorrer das reformas implementadas em várias dimensões (educação, saúde, segurança pública, cultural, social, econômica etc.) do governo federal, nota-se que o modelo gerencial de organização administrativa do espaço público focou seus objetivos em duas frentes: de um lado, predominou a incorporação por parte dos gestores públicos de técnicas e ferramentas gerenciais como as utilizadas no meio privado; de outro, houve a propagação de ideias de Estado mínimo e enxugamento da "máquina pública”. Ambas as frentes de 
perspectivas gerencialistas procuravam reestruturar o Estado-Nação nos moldes da administração privada e das orientações advindas do processo de globalização (BRESSER-PEREIRA, 2005).

Paula (2005), ao analisar o papel da administração pública gerencial no Estado brasileiro, constatou um conjunto de limites e pontos positivos que vem caracterizando esta forma de administrar as instituições públicas:

Em relação aos limites da administração pública gerencial são considerados aspectos como: a) centraliza o processo decisório e não estimula a elaboração de instituições políticas mais abertas à participação social; b) enfatiza mais as dimensões estruturais do que as dimensões sociais e políticas de gestão; c) implementou um modelo de reforma e gestão pública que não foi construído no país. Em contrapartida, os pontos positivos deste modelo de gestão desenvolveram-se sob a orientação de duas características básicas: primeiramente, possui clareza em relação à organização do aparelho de Estado e métodos de gestão. Segundo, alguns métodos gerencialistas vêm melhorando a eficiência do setor público, especialmente no campo econômico-financeiro. (PAULA, 2005, p. 178).

Se um dos focos da administração pública burocrática estava nos resultados; com a emergência da administração pública gerencial, o Estado brasileiro amplia suas funções para além dos resultados, ao enfatizar a importância dos princípios administrativos de eficiência e eficácia tendo nas ações gerenciais pontos norteadores para a orientação das funções estatais. Este cenário está diretamente ligado à importância dada às ferramentas de planejamento e controle, que passaram a ser mais utilizadas sobre os resultados das instituições públicas em detrimento das reais demandas da sociedade (MARTINS, 1997; MOTTA, 2007).

Para estes autores, guardadas as peculiaridades empíricas de seus estudos, o cenário atual vem apontando necessidades de redesenhar o Estado brasileiro desde a sua maneira de atuação até as formas de organização do espaço público, na medida em que a oferta dos bens e serviços públicos torna-se mais competitiva e diferenciada e faz emergir demandas que vão de encontro à utilização de "modelos inovadores" de como administrar as instituições públicas em comparação aos "modelos tradicionais de administração pública".

Assim, constata Abrucio (1998) que, a partir da segunda metade do século passado, a reforma do Estado se tornou uma prerrogativa essencial em quase todo o mundo, contribuindo para que a administração pública gerencial se tornasse uma opção viável para reorganizar as orientações de gestão praticadas nas instituições públicas. Para Abrucio (1998), tal opção somente foi amplamente difundida nas modernas democracias a partir do momento em que a crise mundial da década de 70 reorientou os procedimentos econômicos e as intervenções estatais para um novo cenário que começava a se fazer presente em proporções globais.

A administração pública gerencial é frequentemente identificada com as ideias neoliberais por outra razão. As técnicas de gerenciamento são quase sempre introduzidas ao mesmo tempo em que se implantam programas de ajuste estrutural que visam a enfrentar a crise fiscal do Estado. Como observa Nunberg $(1995$, p. 11), a primeira fase da reforma, geralmente chamada de 'gerenciamento diluído', consistiu em medidas para reduzir o gasto público e o número de funcionários, como resposta às limitações fisscais. Isso ocorreu na Grã-Bretanha, no Canadá, na Austrália, na Nova Zelândia, no Japão e nos EUA. E ocorre atualmente na América Latina, incluindo o Brasil, onde a reforma administrativa é formalmente orientada para substituir a administração pública burocrática por uma administração pública gerencial. (BRESSER-PEREIRA, 2005, p. 31).

Todavia Paula (2005) observa que governos de diversos países aderiram, nos anos 80 e 90, ao modelo de administração pública gerencial fundamentado nos princípios do neoliberalismo tendo como pretensão fazer valer as demandas de reformas que o Estado necessitava, bem como contribuir para a reestruturação dos 
procedimentos e das práticas até então utilizadas na maioria das nações desenvolvidas ou em processo de desenvolvimento. Nesse contexto, observa-se que as principais críticas feitas ao modelo gerencial de organização apontam o fato de que esse modelo, ao valorizar as responsabilidades de cunho deliberativo, enfrenta constantes obstáculos advindos dos costumes e das práticas tradicionais que ainda se perpetuam no seio das instituições públicas. No entanto, a administração pública gerencial ainda se configura como um modelo de gestão em fase de consolidação e maturidade no que tange ao acompanhamento das novas tendências gerenciais usualmente praticadas no âmbito da globalização.

Assim, nos anos iniciais do terceiro milênio, o modelo de administração pública gerencial começou a demonstrar pontos problemáticos de estrangulamento, e novas propostas de administrar a "coisa pública" começaram a chamar a atenção dos "reformadores do Estado". Apesar de raríssimos embasamentos empíricos ou experiências que comprovassem a sua eficácia, a "administração pública societal" surge como um dos modelos alternativos a serem utilizados no espaço público em detrimento das fragilidades e limitações demonstradas pela administração pública gerencial.

As características e os limites da administração pública gerencial resultaram em uma concepção limitada de democracia, que começou a gerar contestações de setores da sociedade ligados aos movimentos sociais. Isso contribuiu para o processo de crise da aliança social-liberal, que aumentou com o fracasso da "novíssima dependência" quanto ao desenvolvimento do país, abrindo espaço para a ascensão de uma nova vertente de reforma e gestão do Estado: a vertente societal. Em relação à democracia, verificamos que o Estado pós-reforma confiou à burocracia pública as decisões estratégicas e optou por uma abordagem política instrumental. O resultado foi uma democracia meramente formal, que enfatiza as instituições e os procedimentos administrativos, e não uma democracia voltada para o desenvolvimento da dimensão sociopolítica da gestão. O governo da aliança socialliberal foi marcado pela concepção formal e restrita de democracia, o que não chega a surpreender, pois isso já é perceptível nas suas raízes. (PAULA, 2005, p. 149).

A partir do histórico apresentado fica evidente que a administração pública gerencial de base neoliberal não conseguiu realizar todas as etapas propostas em seu bojo, principalmente as que se referem à consolidação e permanência, em nossa época, do "Estado mínimo". No entanto, não se podem desconsiderar as importantes contribuições feitas pelo exercício da administração pública gerencial no processo de gerir e organizar o Estado, bem como o progresso atingido até então, apesar dos limites que acompanham este modelo de gestão da "coisa pública" até os dias atuais.

Porém, neste estudo, não se optou por discutir a "administração pública societal", pelo fato de que ainda não existem consensos ou claras definições conceitual-empíricas sobre o que é ou como deveria ser esse "novo modelo". Sabe-se somente que a administração pública societal busca, de modo geral, a promoção de iniciativas voltadas a maior participação popular nas decisões governamentais, controle permanente dos gastos e investimentos públicos e o fortalecimento dos princípios do Estado Democrático de Direito. Assim, salienta-se que as fases de administração pública (patrimonial, burocrática e gerencial) vivenciadas no espaço público brasileiro não se anulam mutuamente, já que elementos característicos dessas três fases podem ser encontrados de forma isolada ou aglutinada (hibridismo) nas práticas políticas e governamentais ainda existentes no Brasil.

\section{Considerações Pontuais}

As discussões em torno das temáticas "capital social", "institucionalismo" e "modelos de administração pública" convidam-nos a refletir sobre as mudanças ocorridas nas sociedades modernas, principalmente no 
que se refere às formas de governo e às tendências das relações entre Estado e sociedade que vêm ocorrendo atualmente no mundo globalizado.

Capital social no contexto sociopolítico, econômico e cultural diz respeito às transformações que vêm modificando as relações entre cidadãos e governo, e de governos para com os cidadãos. Os exemplos de casos sobre a descentralização política, a participação popular direta, a formação cidadã e o espírito de grupo têm norteado as ações governamentais e a aplicação de políticas públicas em cenários plurais. Tais cenários materializam-se por meio de conselhos municipais, associações de moradores de bairros, cooperativas, ONGs e tantos outros movimentos sociais e empresariais que se articulam para prover os interesses divergentes da sociedade.

O institucionalismo surge como uma lente capaz de permitir a compreensão da legitimação de ações públicas por meio de valores, estrutura de poder, hierarquia, cultura e normas, que fomentam os debates em torno do "velho" e do "novo" institucionalismo no âmbito dos estudos organizacionais e da administração pública.

Quanto aos modelos de administração pública discutidos no contexto brasileiro, nota-se a valorização do hibridismo como ponto de partida para gerir a "máquina pública". Isto mostra que não se faz uso de uma forma pura de gestão pública no Brasil. Normalmente, opta-se pela combinação dos tipos de administração pública historicamente conhecidos: patrimonialismo, burocratismo e gerencialismo. Assim, elementos característicos desses três tipos são encontrados de forma híbrida no Brasil nas práticas políticas, na gestão de instituições públicas e sociais e, especialmente, no âmbito governamental. Portanto, conclui-se que, para compreender melhor os tipos de administração pública historicamente observados e desenvolver um modelo mais adequado à participação cívica da sociedade moderna brasileira, faz-se necessário analisar as práticas de gestão institucionalizadas, especialmente a reprodução moderna das práticas patrimonialistas, frente aos desafios de superação das relações assimétricas entre Estado e sociedade.

Assim, com o recorte literário realizado ao longo deste estudo, pretendeu-se colocar em discussão temas conceituais que envolvem o modelo de administração pública tradicional de organização, apontando suas limitações, problemas e pontos de estrangulamento, ao mesmo tempo em que foi apresentado e discutido o "Modelo Gerencial de Administração Pública", que se apresenta sob "orientações inovadoras" de gestão pública que não se alinham totalmente ao modelo tradicional. Tal modelo de administração pública propõe formas alternativas de gestão ao modelo burocrático tradicional, em rompimento com este. Apresenta, no entanto, apenas mudanças superficiais, incorporações conceituais e formas de aperfeiçoamento ao modelo tradicional já existente. A histórica capacidade institucional de adaptação do modelo burocrático nas instituições públicas é comprovada, principalmente, pela onipresença marcante de rotinas e padrões de procedimentos operacionais formalmente institucionalizados, que, na maioria das vezes, restringe ou afasta o envolvimento da população nas decisões públicas, que passam a se comportar apenas como espectadores.

Essas considerações pontuais não têm a pretensão de saturar o assunto investigado, já que existe um conjunto de orientações recentes sobre "capital social", "institucionalismo" e "administração pública" que têm permitido o constante (re)pensar das práticas institucionais, bem como instigado pesquisas empíricas no âmbito das instituições públicas.

\section{Referências}

ABRUCIO, L. F. Os avanços e os dilemas do modelo pós-burocrático. São Paulo: FGV, 1998.

BOURDIEU, P. The forms of capital. In: RICHARDSON, J. (Ed.) Handbook of theory and research for the sociology of education. Nova York: Greenwood press, 1986. p. 31-56. 
BOWRING, M. A. De/constructing theory a look at the institucional theory that positivism built. Sage publications: Journal of management inquiry, v. 9, n. 3, p. 258-270, Sept. 2000.

BRESSER-PEREIRA, L. C. Democracia republicana e participativa. Novos estudos CEBRAP, São Paulo, v. 71, p. 77 91, mar. 2005.

BRIGGS, X. S. Social Capital: easy beauty or meaningful resource? Journal of the American Planning Association, v. 70, n. 2, p. 151-158, 2004.

BRUSCO, S. The institutional logic of small-firm economies in Italy and Taiwan. Studies in Comparative International Development (SCID), Springer New York, March, 1990.

BRYMAN, A. Organization studies and the concept of rationality. Journal of management Studies, v. 21, n. 4, 1984.

BULlEN, P. Measuring social capital in five communities. The Journal of Applied Behavioral Science, v. 36, n. 1, p. 23-42, 2000

BURRELL, G.; MORGAN, G. Sociological paradigms and organizational analysis. London: Heinemann, 1979.

CASEY, C. Bureaucracy Re-enchanted? Spirit, experts and authority in organizations. Organization, London, v. $11, \mathrm{n}$. 1, p. 59-79, 2004.

COLEMAN, J. S. Foundations of social theory. Cambridge, MA: Harvard University Press, 1990.

DIMAGgIO, P. J. (Ed.). The new institutionalism in organizational analysis. London: Sage, 1991.

DRUCKER, P. F. Administrando em tempos de grandes mudanças. São Paulo: Pioneira, 1999.

FAORO, R. Os donos do poder: formação do patronato político brasileiro. 10. ed., v. 2, São Paulo: Globo/Publifolha, 2000.

FRANÇA FILHO, G. C. Para um olhar epistemológico da administração: problematizando o seu objeto. Salvador: Mandacaru, 2004.

FREY, K. Políticas públicas: um debate conceitual e reflexões referentes à prática da análise de políticas públicas no Brasil. Planejamento e políticas públicas, Brasília, IPEA, n. 21, jun. 2000

FUKUYAMA, F. Social capital and the global economy. Foreign Affairs, n. 74, v. 5, p. 89-103, 1995.

HALL, P. A.; TAYLOR, R. C. R. As três versões do neo-institucionalismo. Lua Nova Revista de Cultura e Política, n. 58, p. $193-223,2003$.

HASSARD, J. Sociology and organizational theory: positivism, paradigms and postmodernism. London: Cambridge, 1993.

HOLANDA, S. B. de. Raízes do Brasil. São Paulo: Brasiliense, 2000.

LANNA, M. P. D. A dívida divina: troca e patronagem no Nordeste brasileiro. Campinas-SP: Editora da UNICAMP, 1995.

LEAL, V. N. Coronelismo, enxada e voto: o município e o regime representativo no Brasil. 6. ed. São Paulo: Alfaomega, 1993.

MACHADO-DA-SILVA, C.; GONÇALVES S. A mudança organizacional, esquemas interpretativos e contexto institucional: dois casos ilustrativos. Revista de estudos organizacionais, Maringá, v. 1, n. 2, p.1-16, jul. 2000. 
MARCH, J. G.; OLSEN, J. P. Rediscovering institutions: the organizational basis of politics. New York: The Free Press, 1989.

MARTINS, H. F. Burocracia e a revolução gerencial: a persistência da dicotomia entre política e administração. Revista do Serviço Público, Brasília, ano 48, n. 1. jan./abr. 1997.

MORGAN, G. Paradigms, metaphors and puzzle solving in organization theory. Administratives Science Quarterly, Ithaca, v. 25, n. 4, p. 605-622, Dec. 1980.

MOTTA, P. R. A modernização da administração pública brasileira nos últimos 40 anos. Rev. Adm. Pública, v. 41, n. especial, 2007.

NEE, V. The new institutionalism in sociology. New York: Russell Sage Foundation, 1998.

NORTH, D. C. Institutions, institutional change and economic performance. New York: Cambridge University Press, 1990.

NUNES, E. A gramática política do Brasil: clientelismo e insulamento burocrático. Brasília: ENAP, 1997.

PAULA, A. P. P. Por uma nova gestão pública: limites e potencialidades da experiência contemporânea. Rio de Janeiro: FGV, 2005.

PORTES, A. Social capital: Its origins and applications in modern sociology. Annual Review of Sociology, 24, ABI/INFORM Global, 1998. p. 0-12.

PUTNAM, R. D. Comunidade e democracia: a experiência da Itália moderna. Trad. de Luiz Alberto Monjardim. 3. ed. Rio de Janeiro: FGV, 2002.

REIS, B. P. W. Capital social e confiança: questões de teoria e método. Revista de Sociologia Política, Curitiba, 21, p. 35-49, nov., 2003.

SCOTT, W. R. Institutions and organizations. Thousand Oaks, CA: Sage, 1995.

TOLBERT, P. S., ZUCKER, L. G. A institucionalização da teoria institucional. In: CLEGG, S. R. et al. Handbook de Estudos Organizacionais: modelos de análise e novas questões em estudos organizacionais. v. 1. São Paulo: Atlas, 2006. p. 194-217.

UPHOFF, N. Understanding social capital: learning from the analysis and experience of participation. Washington: The Word Bank, 2000.

WEBER, M. Economia e sociedade: fundamentos da sociologia compreensiva. Brasília: Editora UnB, v. 2, 1999. 